\title{
Spatial modeling of the spread of scabies and environmental sanitation as a risk factor among schoolchildren: a case-control study
}

\author{
Yudhi Wibowo*, Nendyah Roestijawati*, Diah Krisnansari*, and Agoes Y Purnomo**
}

\begin{abstract}
\section{BACKGROUND}

Scabies is a World Health Organization neglected tropical disease common in children in low-and middle-income countries. The prevalence of scabies, especially in tropical countries, is still quite high at more than 200 million cases per year. Transmission of scabies is predominantly via skin-to-skin contact. The purpose of the study was to determine the epidemiology of clinical scabies among schoolchildren and spatial modeling using geographic information systems (GIS).
\end{abstract}

\section{METHODS}

A study of unmatched case-control design with a ratio of $1: 1$ was performed to identify specific risk factors of scabies. Cases were patients with clinical scabies and controls were healthy people in the area. A total of 100 students were involved in the study. Simple and multiple logistic regression was used to test any association between the variables. GIS modeling was used to determine the spatial distribution of clinical scabies based on 69 cases.

\section{RESULT}

There was a significant association between the level of environmental sanitation and the prevalence of clinical scabies $(\mathrm{OR}=2.53 ; 95 \%$ C.I. 1.115.74). Multivariate analysis showed that the level of environmental sanitation was significant $(\mathrm{AOR}=3.05 ; 95 \%$ C.I. 1.19-7.81). Risk factors for developing clinical scabies increased to 3 times after considering other risk factors, namely gender, age group and respondent education level. Analysis of average nearest neighbor distance showed that the spatial distribution of clinical scabies was clustered.

\section{CONCLUSIONS}

The distribution of clinical scabies was spatial clustering, and prediction of transmission in a clockwise direction with Southeast and Northwest ellipses.

Keywords: Risk factors, spatial analysis, scabies, schoolchildren
*Department of Public Health \& Community Medicine,

Faculty of Medicine,

Jenderal Soedirman University

Purwokerto

**Magetan District Health Office, East Java

\section{Correspondence:}

dr. Yudhi Wibowo, M.PH

Department of Public Health \&

Community Medicine, Faculty of

Medicine, Jenderal Soedirman

University Purwokerto

Jl. Dr. Gumbreg No. 1, Mersi,

East Purwokerto 53112

Phone: +62281-622022

Email:

dryudhiwibowo2005@gmail.com

ORCID: 0000-0001-7523-2170

Date of first submission, December 12, 2018

Date of final revised submission, April 10,2020

Date of acceptance, April 10, 2020

This open access article is distributed under a Creative Commons AttributionNon Commercial-Share Alike 4.0 International License

Cite this article as: Wibowo Y, Roestijawati N, Krisnansari D, Purnomo AY. Spatial modeling of the spread of scabies and environmental sanitation as a risk factor among schoolchildren: a case-control study. Univ Med 2020;39:52-62. doi: 10.18051/UnivMed.2020.v39.55-62 


\section{INTRODUCTION}

The prevalence of scabies, especially in tropical countries, is still quite high at more than 200 million cases per year. The five countries with the largest scabies burden were Indonesia (agestandardized DALYs 153.86), China (138.25), Timor-Leste (136.67), Vanuatu (131.59), and Fiji (130.91). ${ }^{(1)}$ The prevalence of scabies in Indonesia, according to the Indonesian Ministry of Health, has declined from year to year, as seen from the prevalence data for 2008, 2009 and 2013 of $5.60 \%-12.96 \%, 4.9-12,95 \%$, and $3.9-6 \%$, respectively. Although there has been a decline in scabies prevalence, Indonesia is still not free from this disease, which still is one of the infectious diseases in Indonesia that constitute a public health problem. ${ }^{(2)}$

Scabies transmission is apparently easy due to environmental factors and unhealthy behavior. The incidence of scabies has risen to a higher level than 20 years ago and the disease is mostly found in orphanages, dormitories of Islamic boarding schools, prisons, hospitals, and places with poor sanitation. ${ }^{(3)}$

In classical population-based and ecological studies, the description of disease-navigating webs is based on the analysis of differences in the temporal and spatial distribution of disease prevalence between different host species, sexes, ages, and geographical locations..$^{(4,5)}$ There was a study on the spatial distribution of scabies, but this was done during a nosocomial outbreak in an inpatient ward for cases of senile dementia. ${ }^{(6)}$ Spatial analysis of the distribution and spread of clinical scabies in human hosts in the broader area has not been performed until recently. Therefore, the present study aimed to identify the distribution and spread of clinical scabies by means of spatial analysis and to examine whether there is a relationship between demographic characteristics, level of knowledge about scabies, and environmental sanitation.

\section{METHODS}

\section{Research design}

This was an unmatched case-control design with a ratio of $1: 1$. The study was conducted in 8 months from 1 March to 28 November 2018 in Banyumas district, in the southern region of Central Java, Indonesia.

\section{Research subjects}

The subjects in this case study comprised clinical scabies patients who had been diagnosed by doctors in the last three months based on the cardinal signs of scabies among students obtained from secondary data at the Jatilawang sub-district Health Center, Banyumas district, and the results of medical examinations in boarding schools (elementary, junior high and senior high) of Tinggarjaya village, Jatilawang sub-district. The control group consisted of young people without clinical scabies from one sub-district. All schoolchildren from a given boarding school were the target population of this study. The sample size of 50 subjects per group was determined based on $\mathrm{OR}=2.56,{ }^{(7)}$ significance level $\alpha=0.05$, and power of the test $=80 \%$. The subjects were randomly selected using cluster and simple random sampling. Spatial analysis was based on 69 clinical scabies cases.

\section{Data collection}

Data were collected by interview, using a validated semi-structured questionnaire comprising items on socio-demographic characteristics (sex, age, level of education), level of knowledge, and environmental sanitation associated with scabies. The age of the subjects was divided into two categories, namely $<12$ years and $\geq 12$ years. The education level was categorized into elementary school, junior high school, and senior high school. The level of knowledge and environmental hygiene was categorized as deficient (score $<20$ ) and good ( score $>20$ ). 


\section{Spatial analysis}

This study used the geographic information system (GIS) to determine the distribution and spatial modeling of clinical scabies cases in Jatilawang sub-district, Banyumas district. The spatial analysis included average nearest neighbor distance, kernel density, and analysis of the standard deviational ellipse (SDE). ${ }^{(8)}$ The nearest neighbor analysis was an approach to look at the pattern of the spread of clinical scabies cases. The calculated average nearest neighbor (ANN) score was used to determine the distribution pattern of clinical scabies cases. An average nearest neighbor may be calculated using the formula: ANN= ÏO / ÏE, where ÏO is the observed mean distance between each feature and their nearest neighbor, and ÏE is the expected mean distance for the features given a random pattern. However, in practice, ANN values are calculated using Geographical Information Systems (GIS) software. ANN values are inferred based on the value of the expected mean distance. They are represented by (i) $\mathrm{ANN}=1$ indicating the occurrence of a random pattern, (ii) ANN $<1$ indicating the incidence of crowding (clustered), and (iii). ANN $>1$ indicating the incident spread (dispersed).${ }^{(9)}$

Estimated kernel density is a method for estimating the density of a point in an area. Therefore, estimation of kernel density can be used to map the risk of the area affected by the disease by knowing the density of the patients. ${ }^{(10)}$

The standard deviational ellipse (SDE) was used to analyze trends and patterns of dispersion of clinical scabies. The standard deviational ellipse is a summary of central tendency and dispersion in two dimensions, as well as a directional trend. Two points were used as the basis for the distribution of point locations on SDE, namely central tendency and dispersion. Central tendency uses the center of the mean and dispersion refers to the spread of the mean center bounded by the ellipse. Standard deviational ellipse models can be used to gain a better understanding of the geographical aspects of the phenomenon and identify the cause of an event, based on specific geographic patterns. ${ }^{(11)}$

\section{Data analysis}

An odds ratio was used to examine the association between variables, with significant variables being included in a model for multiple logistic regression.

\section{Ethical clearance}

The study was approved by the Commission on Health Research Ethics, Faculty of Medicine, Jenderal Soedirman University with Ref. no: 1412/ UN23.07.5.1/PN.1/2018.

\section{RESULTS}

The results of the analysis of demographic relations, level of knowledge and environmental sanitation with the incidence of scabies are presented in Table 1.

Table 1 shows that the results of the bivariate analysis were statistically significant on the level of environmental sanitation $(\mathrm{p}=0.025)$. A multivariate analysis was conducted to find out the most influential risk factors for the occurrence of scabies. Risk factors that had a p-value of $<0.25$ were included in the multivariate analysis, consisting of gender, age, education level, and level of environmental sanitation. The results of the multivariate analysis are presented in Table 2.

Table 2 shows that the risk factors for environmental sanitation are statistically significant for the prevalence of clinical scabies (AOR $=3.05 ; 95 \%$ CI 1.19-7.81). The center of cases, with a buffer radius of $1 \mathrm{~km}$, was presented in Figure 1.

Based on the average nearest neighbor distance analysis, the distribution of the prevalence of clinical scabies was clustered as a Z score of $-15.888(\mathrm{p}<0.05)$. The study also reveals that kernel density analysis shows the low-density category (0 - 165.796.010,7 square map units), as presented in Figure 2.

The results of the standard deviational ellipse (SDE) analysis to determine the trend of 
Table 1. Demographic analysis, level of knowledge and environmental sanitation of the subjects

\begin{tabular}{|c|c|c|c|c|c|c|c|}
\hline \multirow{2}{*}{ Variable } & \multicolumn{2}{|c|}{ Case } & \multicolumn{2}{|c|}{ Control } & \multirow{2}{*}{ OR* } & \multirow{2}{*}{$95 \%$ CI } & \multirow{2}{*}{ p value } \\
\hline & $\mathrm{n}$ & $(\%)$ & n & $(\%)$ & & & \\
\hline \multicolumn{8}{|l|}{$\overline{\operatorname{Sex}}$} \\
\hline Female & 33 & 60 & 26 & 52 & 1.79 & $0.80-4.01$ & 0.156 \\
\hline Male & 17 & 40 & 24 & 48 & & & \\
\hline \multicolumn{8}{|l|}{ Age group (years) } \\
\hline$\leq 12$ & 17 & 34 & 24 & 48 & 0.55 & $0.24-1.25$ & 0.155 \\
\hline$>12$ & 33 & 34 & 26 & 52 & & & \\
\hline \multicolumn{8}{|l|}{ Level of education } \\
\hline Elementary school & 11 & 22 & 12 & 24 & 0.55 & $0.19-1.60$ & 0.276 \\
\hline Junior high school & 16 & 32 & 24 & 48 & 0.40 & $0.16-1.01$ & 0.052 \\
\hline Senior High school & 23 & 46 & 14 & 28 & ref & & \\
\hline \multicolumn{8}{|l|}{ Level of knowledge } \\
\hline Low & 22 & 44 & 24 & 48 & 0.85 & $0.38-1.87$ & 0.688 \\
\hline Good & 28 & 56 & 26 & 52 & & & \\
\hline \multicolumn{8}{|l|}{ Environmental sanitation } \\
\hline Low & 26 & 52 & 15 & 30 & 2.52 & $1.11-5.74$ & $0.025^{*}$ \\
\hline Good & 24 & 48 & 35 & 70 & & & \\
\hline
\end{tabular}

* OR : Odds ratio

distribution of clinical scabies in the Jatilawang sub-district in 2018 were presented in Figure 3.

The direction of the spread of clinical scabies in Jatilawang sub-district was clockwise with angle of y-axis rotation $83.25^{\circ}, 1^{\text {st }} \mathrm{SDE}$ : $y$-axis length: $391 \mathrm{~m}$, $\mathrm{x}$-axis length: $1.683 \mathrm{~m}$ and ellipse area: $517 \mathrm{~km}^{2} ; 2^{\text {nd }} \mathrm{SDE}: \mathrm{y}$-axis length: $783 \mathrm{~m}$, $\mathrm{x}$ axis length: $3.366 \mathrm{~m}$ and ellipse area: $2.071 \mathrm{~km}^{2}$. The tendency of the spread of clinical scabies will follow the pattern of the SDE results if the risk factors exist in the area and are uncontrolled. The results of the spatial analysis show that the highest distribution of cases is in Tinggarjaya village, Jatilawang sub-district. As many as 50 subjects with scabies were in the boarding schools in the village. The clinical distribution of scabies W: clustered, with the central cluster in the boarding schools, and had a low density within a radius of $1 \mathrm{~km}$. However, not all cases were identified, so that they did not provide a near-real picture in the field. The sixty-nine cases of scabies consisted of 50 subjects who lived in the boarding school, and 19 young people residing in the surrounding village areas.

\section{DISCUSSION}

With regard to the characteristics of the respondents in the case group, most were of female gender $(60 \%)$. This finding was different from the other studies which reported that $41.2 \%$ to $61.8 \%$ of cases were male. ${ }^{(12-16)}$ This was understandable since the percentage of students in these studies was $58.1 \%$ females, identical with other previous reports. ${ }^{(17-20)}$ The male-to-female ratio on scabies prevalence index, mostly may be

Table 2. Multiple logistic regression analysis of sex, age, level education and sanitation with clinical scabies

\begin{tabular}{lccc}
\hline Variable & AOR & $\mathbf{9 5 \%}$ CI & p value \\
\hline Sex & 0.62 & $0.21-1.86$ & 0.402 \\
Age group & 0.95 & $0.26-3.38$ & 0.938 \\
Level of education & & & \\
$\quad$ Elementary school & 1.02 & $0.17-6.55$ & 0.948 \\
$\quad$ Junior high school & 2.11 & $0.46-5.26$ & 0.821 \\
$\quad$ Senior high school & Ref & & \\
Environmental sanitation & 3.05 & $1.19-7.80$ & $0.020^{*}$ \\
\hline
\end{tabular}




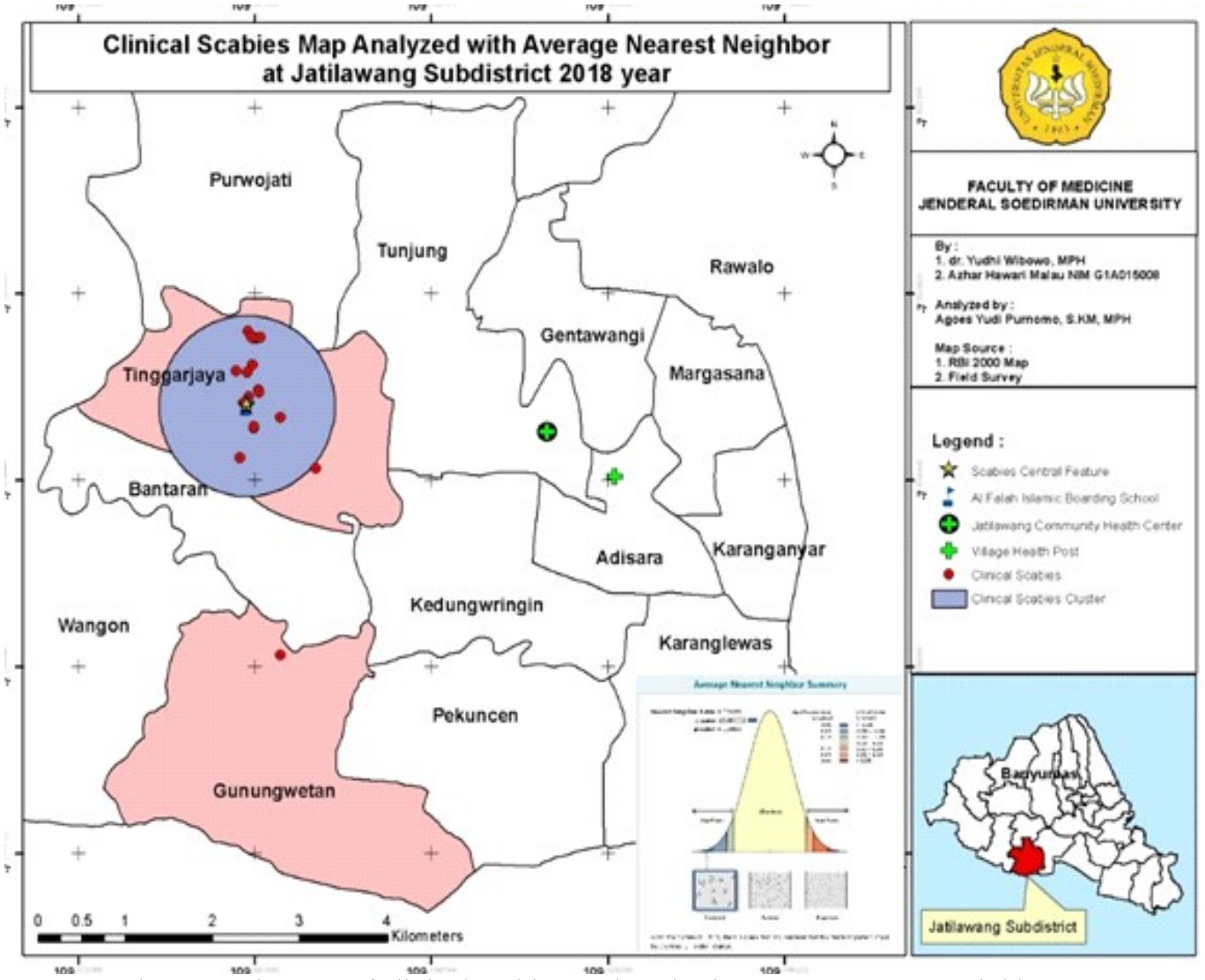

Figure 1. The map of clinical scabies analyzed using average nearest neighbor

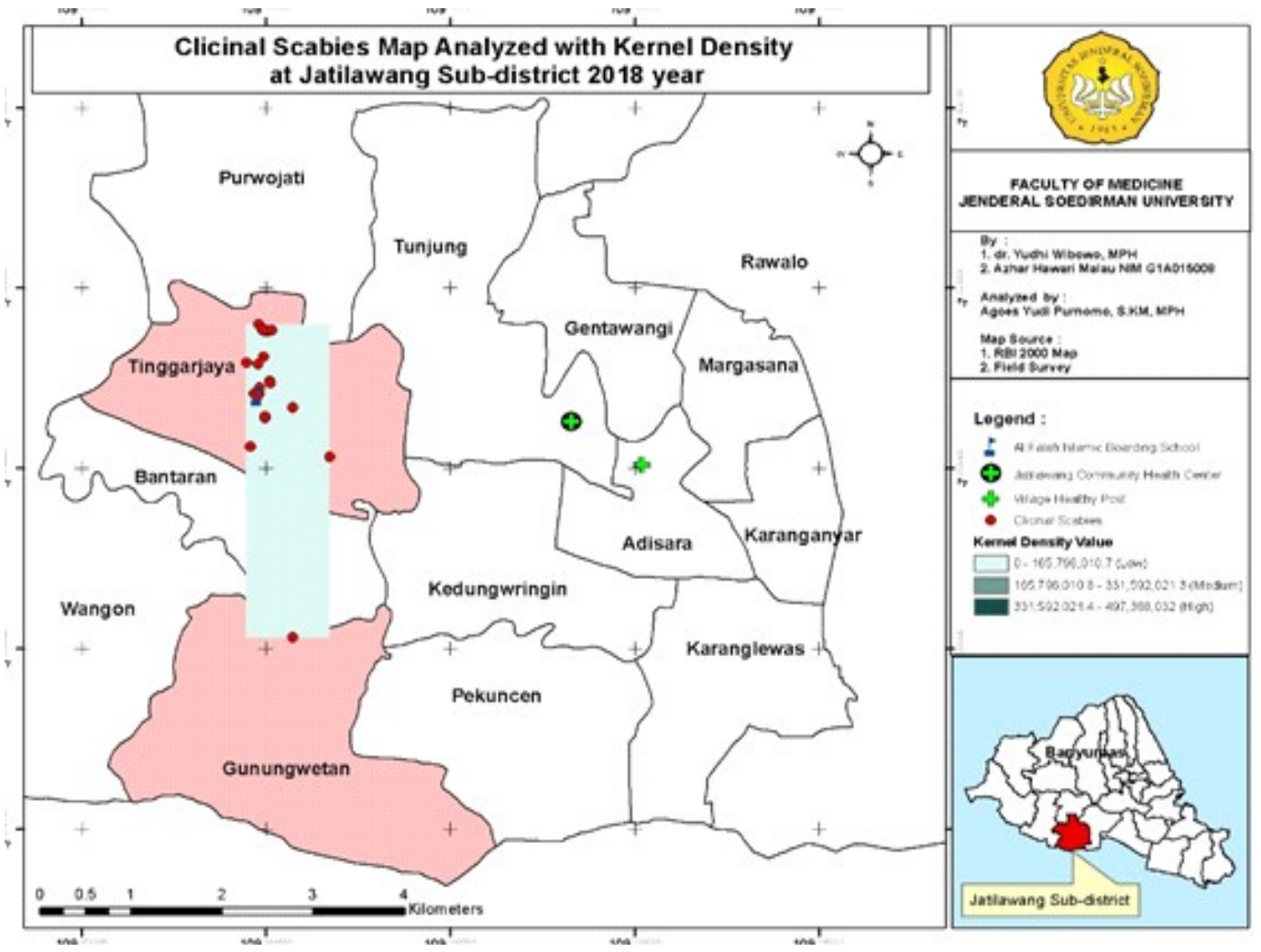

Figure 2. The map of clinical scabies on Kernel Density 


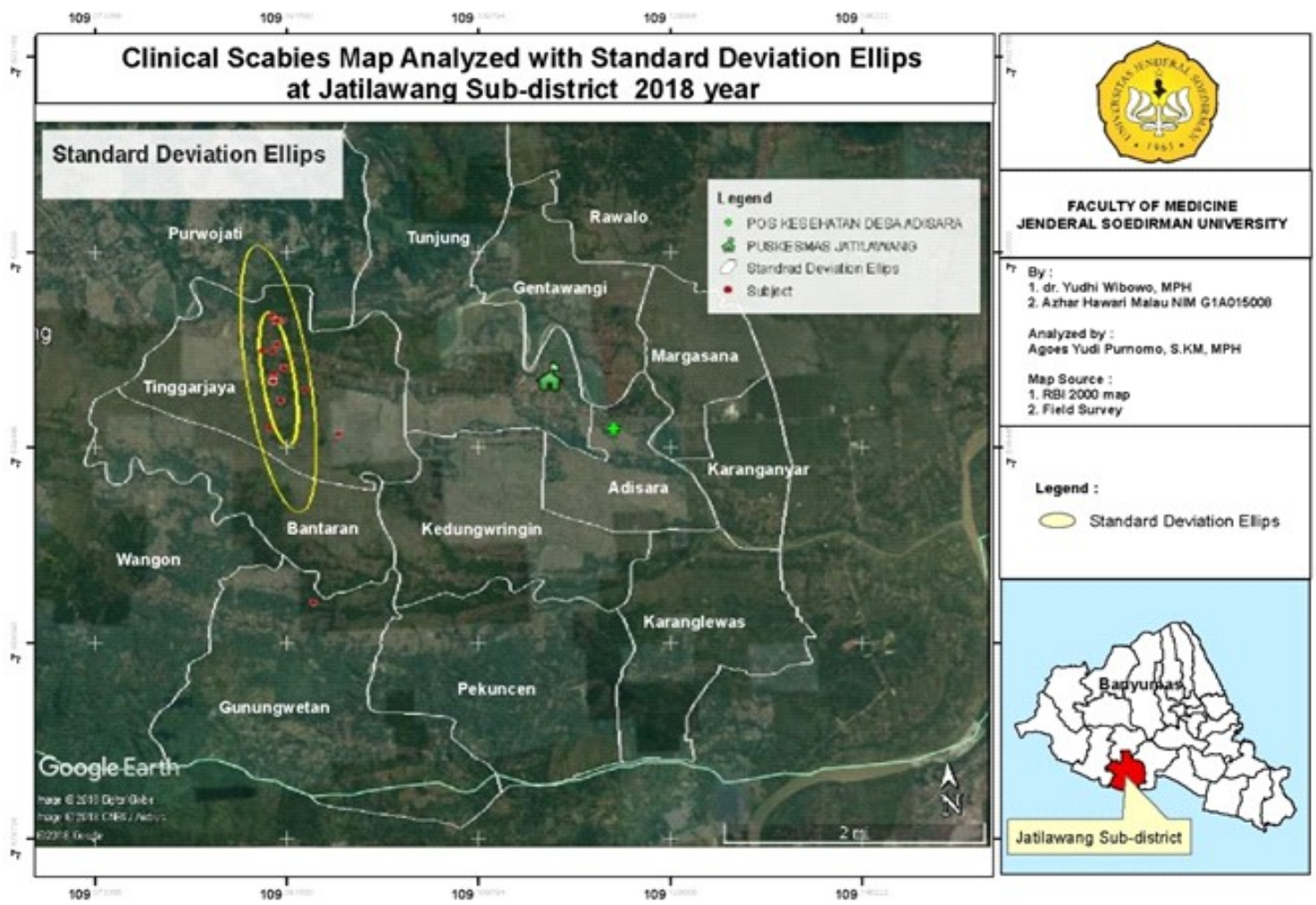

Figure 3. Pattern tendency of clinical scabies

influenced by the number of students at the school. It is not really related to gender, but to health sanitation and daily behavior. Poor sanitation facilitates the development of scabies larvae, whereas poor health behavior worsens the situation and facilitates the transmission of worms. ${ }^{(21)}$

The results showed that as much as $66 \%$ of scabies cases was $>12$ years old. This result is in accordance with the research result of Ugbomoiko et al. ${ }^{(19)}$ which amounted to $46.4 \%$ of cases of scabies aged 11-15 years. Other studies showed $44.2 \%$ of cases of scabies aged 13-18 years. ${ }^{(15)}$ The high prevalence of scabies at age $>12$ years can be associated with length of stay of the students in boarding schools so that they have a higher chance of being exposed to or being infected with scabies in the boarding school. However, the present study did not examine the relationship between length of stay in Islamic boarding schools and incidence of scabies.

Respondents in the scabies group had the highest level of education, namely senior high school or equivalent, or were $>15$ years of age (46\%), while according to previous data by Liu et al., ${ }^{(15)}$ the majority of people with scabies were between 13-18 years of age, this being the junior and senior high school age. We also found that other studies have encountered the highest prevalence in pre-schools, elementary schools and junior high schools. ${ }^{(16,17,19)}$ The school as a place for social community is a suitable place for transmission and movement of scabies larvae. Unlimited relationships and access to games with poor sanitation can make things worse. Schools with a boarding system without proper health management lead to high risks of development of diseases. The high number of students or insufficient space for the school population increases the risk of developing scabies.

Fifty-two percent of subjects in the scabies group have poor behavior in terms of environmental hygiene. Improper daily habit activities have a significant aspect of transmitting scabies to other people. This includes the use of towels alternately, using the 
same prayer tools or accessories, and sleeping together in the same bed or using the same pillows. These factors can increase the risk for suffering from scabies to 2.5 times, and may increase to 3 times after considering other risk factors, including gender, age group, and education level of respondents following multivariate analysis. The risks would increase in overcrowded residential conditions. ${ }^{(20-23)}$

The distribution of clinical scabies prevalence appears to be clustered. The cluster center is in the boarding school (Figures 2 and 3 ) and is related to the risk factors for scabies transmission, namely the density of occupancy and improper behavior of sharing clothes, beds, and others. The pattern of clockwise direction with Southeast and Northwest ellipse appears as the prediction of transmission. If the risk factors remain high in the area and there is no attempt to cope with scabies, there is a tendency for clockwise transmission of scabies with a slope between the directions Southeast and Northwest. To prevent transmission, many efforts are urgently needed in the form of counseling about clean and healthy living behaviors and also treating the patients to cut off the sources of infection. The possibility of monitoring parameters such as temperature and air humidity should be considered, particularly if there are scabies outbreaks.

\section{CONCLUSIONS}

Environmental sanitation was a risk factor of clinical scabies among schoolchildren. The distribution of clinical scabies in Jatilawang was clustered, and the spatial distribution of cases was in a clockwise direction with Southeast and Northwest ellipses.

\section{CONFLICT OF INTEREST}

The authors declare there is no conflict of interest in developing and submitting this manusccript.

\section{ACKNOWLEDGMENT}

The authors thank the Jenderal Sudirman University, The Institute for Research and Community Service, Faculty of Medicine, Banyumas District Health Office and Community Health Care for their cooperation and assistance.

\section{CONTRIBUTORS}

YW and AYP contributed to the conception and study design; NS and PK contributed to statistical analysis and data interpretation; YW contributed to writing the draft preparation; AYP contributed to editing. All authors have read and approved the ûnal manuscript.

\section{REFERENCES}

1. Karimkhani C, Colombara D V, Drucker AM, et al. The global burden of scabies: a cross sectional analysis from the Global Burden of Disease Study 2015. Lancet Infect Dis 2017;17:1247-54. doi: 10.1016/S1473-3099(17)30483-8.

2. Kementerian Kesehatan. Profil Kesehatan Indonesia Tahun 2013. Jakarta: Kementerian Kesehatan RI; 2014.

3. Engelman D, Steer AC. Control strategies for scabies. Trop Med Infect Dis 2018;3:98. doi: 10.3390/tropicalmed3030098.

4. Alasaad S, Permunian R, Gakuya F, Mutinda M, Soriguer RC, Rossi L. Sarcoptic-mange detector dogs used to identify infected animals during outbreaks in wildlife. BMC Vet Res 2012;8:110. https://doi.org/10.1186/1746-6148-8-110.

5. Alasaad S, Granados JE, Fandos P, Cano-Manuel F-J, Soriguer RC, Pérez JM. The use of radiocollars for monitoring wildlife diseases: a case study from Iberian ibex affected by Sarcoptes scabiei in Sierra Nevada, Spain. Parasit Vectors 2013;6:242. doi: 10.1186/1756-3305-6-242.

6. Tsutsumi M, Nishiura H, Kobayashi T. Dementiaspecific risks of scabies: retrospective epidemiologic analysis of an unveiled nosocomial outbreak in Japan from 1989-90. BMC Infectious Diseases 2005;5:85.

7. Ejigu K, Haji Y, Toma A, Tadesse BT. Factors associated with scabies outbreaks in primary schools in Ethiopia: a case-control study. Res Rep Trop Med 2019;10:119-27. doi: 10.2147/ RRTM.S214724. 
8. Elliott P, Wakefield J, Best N, Briggs D. Spatial epidemiology: methods and applications. Oxford: Oxford University Press;2009. DOI: 10.1093/ acprof:oso/9780198515326.001.0001.

9. Diggle P. Applied spatial statistics for public health data. J Am Stat Ass 2012;100:702-3. https:/ /doi.org/10.1198/jasa.2005.s15.

10. Sabel CE, Lötöne M. Cluster of disease. In: GIS in Public Health Practice. Maheswaran R, Craglia. eds. Boca Raton: CRC Press;2014.p:51-68.

11. Lai PC, So FM, Chan KW. Spatial epidemiological approaches in disease mapping and analysis. Boca Raton: CRC Press;2009. p.58-65.

12. Korte LM, Bowen AC, Draper ADK, et al. Scabies and impetigo in Timor-Leste: a school screening study in two districts. PLoS Negl Trop Dis 2018; 12: e0006400. doi: 10.1371/journal.pntd.0006400.

13. Kaburi BB, Ameme DK, Adu-Asumah G, et al. Outbreak of scabies among preschool children, Accra, Ghana, 2017. BMC Public Health 2019; 19: 746. https://doi.org/10.1186/s12889-019-7085-6

14. Sara J, Haji Y, Gebretsadik A. Scabies outbreak investigation and risk factors in East Badewacho District, Southern Ethiopia: unmatched case control study. Dermatol Res Pract 2018;7276938. doi: 10.1155/2018/7276938.

15. Liu JM, Hsu RJ, Chang FW, et al. Increase the risk of intellectual disability in children with scabies. Medicine (Baltimore) 2017; 96: e7108. doi: 10.1097/MD.0000000000007108.

16. Mason DS, Marks M, Sokana O, et al. The prevalence of scabies and impetigo in the Solomon Islands: a population-based survey. PLoS Negl Trop Dis 2016;10:e0004803. doi: 10.1371/journal. pntd.0004803.
17. Romani L, Whitfeld MJ, Koroivueta J, et al. The epidemiology of scabies and impetigo in relation to demographic and residential characteristics: baseline findings from the Skin Health Intervention Fiji trial. Am J Trop Med Hyg 2017;97: 845-50. doi: 10.4269/ajtmh.16-0753.

18. Hegab DS, Kato AM , Kabbash AI, Dabish GM. Scabies among primary schoolchildren in Egypt: sociomedical environmental study in Kafr ElSheikh administrative area. Clin Cosmet Investig Dermatol 2015;8:105-11. doi: 10.2147/CCID. S78287

19. Ugbomoiko US, Oyedeji SA, Babamale OA, Heukelbach J. Scabies in resource-poor communities in Nasarawa State, Nigeria: epidemiology, clinical features and factors associated with infestation. Trop Med Infect Dis 2018;3:59. doi: 10.3390/tropicalmed302005.

20. Inakanti Y. An old disease in new look - short review of literature: scabies. Int J Clin Case Reports 2015;5:1-5.

21. Fuller LC. Epidemiology of scabies. Curr Opin Infect Dis 2013;26:123-6. doi: 10.1097/QCO. 0b013e32835eb851.

22. Davis JS, McGloughlin S, Tong SYC, Walton SF, Currie BJ. A novel clinical grading scale to guide the management of crusted scabies. PLoS Negl Trop Dis 2013; 7:e2387. doi: 10.1371/journal.pntd. 0002387.

23. Arlian LG, Morgan MS. A review of Sarcoptes scabiei: past, present and future. Parasites Vectors 2017;10: 297. https://doi.org/10.1186/s13071-0172234-1. 